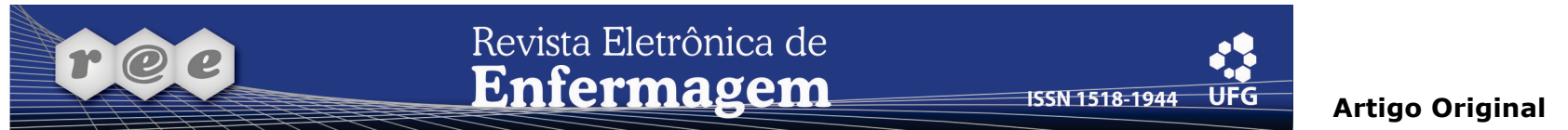

\title{
Desafios gerenciais na transição do adolescente com HIV/Aids por transmissão vertical em serviços de referência
}

\author{
Management challenges for transitioning the adolescent with vertically transmitted HIV/Aids \\ between reference services
}

Desafíos gerenciales de transición del adolescente con VIH/SIDA por transmisión vertical en servicios de referencia

Fabiana Cristine dos Santos ${ }^{1}$, Cintia Koerich ${ }^{2}$, Alacoque Lorenzini Erdmann ${ }^{3}$, Betina Hörner Schlindwein Meirelles ${ }^{4}$ ${ }^{1}$ Enfermeira. Discente do Programa de Pós-Graduação em Enfermagem (PPGENF), nível Mestrado, da Universidade de Santa Catarina (UFSC). Florianópolis, SC, Brasil. E-mail: fcristine@gmail.com.

${ }^{2}$ Enfermeira. Discente do PPGENF/UFSC, nível Mestrado. Florianópolis, SC, Brasil. E-mail: cintia.koerich@ig.com.br.

${ }^{3}$ Enfermeira, Doutora em Filosofia da Enfermagem. Professora Titular do Departamento de Enfermagem da UFSC. Bolsista de Produtividade em Pesquisa do CNPq 1A. Florianópolis, SC, Brasil. E-mail: alacoque@newsite.com.br.

${ }^{4}$ Enfermeira, Doutora em Enfermagem. Professora Adjunta do Departamento de Enfermagem da UFSC. Bolsista de Produtividade em Pesquisa do CNPq - Nível 2. Florianópolis, SC, Brasil. E-mail: betinahsm@ig.com.br.

\section{RESUMO}

Buscou-se caracterizar a estrutura e funcionamento dos serviços de referência em HIV/Aids, em um estado do sul do Brasil, quanto ao cuidado ao adolescente que vive com HIV/Aids por transmissão vertical, considerando o processo de transição entre serviços de referência infantil e adulto, e a contribuição do enfermeiro neste processo como gestor nos serviços de saúde. Estudo de abordagem qualitativa, descritivo, em que foram utilizados para coleta dos dados observação participante e entrevista individual, com 10 participantes. Os dados foram analisados tematicamente, discutidos em três categorias: Apresentando a estrutura dos serviços de referência em HIV/Aids infantil e adulto; Recebendo e acompanhando os adolescentes que vivem com HIV/Aids por transmissão vertical nos serviços de referência; O enfermeiro como gestor nos serviços de referência em HIV/Aids, assim, aponta-se a necessidade de investimentos em infraestrutura, apoio e planejamento das ações gerenciais, capacitação e formação profissional para gestão em saúde afim de que esta transição do cuidado seja de qualidade.

Descritores: Gestão em Saúde; HIV; Adolescente; Cuidados de Enfermagem.

\section{ABSTRACT}

The present study aims at defining the structure and functioning of HIV/Aids reference services in a state in southern Brazil which care for adolescents with vertically transmitted HIV/Aids. It examines the transition process between child and adult reference services and the contribution of nursing professionals towards this process, in the capacity of health services managers. It is a qualitative and descriptive study, whose data was gathered through participative observation and individual interviews with ten participants. The data was analyzed thematically and discussed in three categories: Presenting the structure of child and adult HIV/Aids reference services; Welcoming and accompanying adolescents with vertically transmitted HIV/Aids to reference services; The nursing professional as a health care manager in HIV/Aids reference services, which pointed to the necessity for investments in infrastructure, support and planning of management actions, health management professional training and education, in order to assure the quality of care transition.

Descriptors: Health Management; HIV; Adolescent; Nursing Care.

\section{RESUMEN}

Se buscó caracterizar la estructura y funcionamiento de servicios de referencia en VIH/SIDA en un estado del sur de Brasil en el cuidado al adolescente que vive con VIH/SIDA por transmisión vertical, considerando el proceso de transición entre servicios de referencia infantiles y de adultos, y la contribución del enfermero al proceso como gestor en los servicios de salud. Estudio cualitativo, descriptivo, con datos recolectados mediante observación participante y entrevista individual, con diez sujetos. Datos analizados temáticamente, discutidos según tres categorías: Presentando la estructura de servicios de referencia en VIH/SIDA infantil y de adultos; Recibiendo y siguiendo adolescentes que viven con VIH/SIDA por transmisión vertical en servicios de referencia; El enfermero como gestor en servicios de referencia en VIH/SIDA, que determinaron necesidad de inversiones estructurales, apoyo y planificación de acciones gerenciales, capacitación y formación profesional para gestión en salud, objetivando que dicha transición del cuidado sea de calidad.

Descriptores: Gestión en Salud; VIH; Adolescente; Atención de Enfermería. 


\section{INTRODUÇÃo}

A Síndrome da Imunodeficiência Humana (Aids) vitimou mais de 25 milhões de pessoas desde 1981, e estima-se que mais de 30 milhões estão infectadas com o vírus do HIV em todo o mundo(1). O Vírus da Imunodeficiência Humana (HIV) é mais comumente transmitido por meio de relação sexual desprotegida com um parceiro infectado, contudo outra principal via de transmissão é a vertical ${ }^{(1)}$, o que leva crianças e adolescentes a representar uma população vulnerável à infecção pelo HIV e adoecimento pela Aids $^{(2)}$.

Desde o início da epidemia investimentos foram realizados para combater o vírus da Aids, de forma a garantir a sobrevivência dos portadores, diante da inexistência de cura. Como consequência um grupo de crianças infectadas por transmissão vertical sobreviveu e chega hoje à adolescência como a primeira geração que nasceu infectada pelo HIV e adoece com a Aids ${ }^{(3)}$.

Diante da cronicidade da Aids, a temática da transição dos adolescentes que vivem com HIV/Aids por transmissão vertical, do serviço infantil para o adulto, tem sido tema de discussões entre os profissionais dos serviços de referência, dentre eles o enfermeiro, sendo que se deparam e precisam enfrentar essa transição sem um adequado preparo para lidar com as questões e situações apresentadas por esse público específico ${ }^{(4)}$. Além disso, este acompanhamento é associado a dificuldades de várias naturezas, dentre elas, questões estruturais e de organização dos serviços ${ }^{(4)}$.

Neste contexto, inserido no âmbito dos serviços de referência, o enfermeiro como profissional responsável pela gestão dos serviços de enfermagem, de acordo com a lei do exercício profissional n.7498 de $1986^{(5)}$, busca a integralidade das áreas administrativas, assistenciais e de ensino/pesquisa visando a qualidade do atendimento. Atualmente, as exigências em relação a atuação do enfermeiro incluem além da gerência de enfermagem, o conhecimento e a interação com todo o ambiente organizacional, o que permite uma maior contribuição deste profissional para o sucesso da instituição(6).

Observa-se a urgência de estudos que avancem no sentido de buscar desvelar as necessidades de cuidado do adolescente com HIV/Aids no processo de transição entre os serviços de referência infantil e adulto ${ }^{(7)}$ em suas múltiplas dimensões, e que evidenciem a atuação do enfermeiro enquanto gestor do cuidado a esta população específica, promovendo melhores práticas no cuidado prestado e auxiliando os demais profissionais da equipe de saúde neste processo.
Assim, surgem como questionamentos do estudo: Como os serviços de referência em HIV/Aids estão estruturados para atender o adolescente com HIV/Aids por transmissão vertical? Como o adolescente com HIV/Aids por transmissão vertical está sendo acompanhado nestes serviços? Como o enfermeiro contribui para este cuidado como gestor nos serviços de saúde?

O objetivo desta pesquisa buscou caracterizar a estrutura e funcionamento dos serviços de referência em HIV/Aids de um estado do sul do Brasil no cuidado ao adolescente que vive com HIV/Aids por transmissão vertical, considerando o processo de transição entre os serviços de referência infantil e adulto, assim como a contribuição do enfermeiro neste processo como gestor nos serviços de saúde.

Este estudo poderá contribuir com respostas para o melhor enfrentamento e continuidade do cuidado na transição destes adolescentes do serviço infantil para o adulto, bem como trazer contribuições aos demais serviços clínicos que atendem pacientes crônicos que vivenciam esta situação.

\section{MÉTODO}

Estudo de natureza qualitativa, do tipo participante, de caráter exploratório e descritivo. As instituições escolhidas para desenvolvimento da pesquisa foram dois hospitais públicos de referência estadual em infectologia, localizados no sul do Brasil. Tais instituições dispõem de atendimento para pessoas com HIV/Aids em ambulatório, hospital-dia e unidades de internação. A coleta de dados foi realizada no período de março a junho de 2012, nos serviços de ambulatório destes hospitais, local em que os adolescentes realizavam acompanhamento.

Para a coleta de dados foi realizada observação participante nos 30 dias iniciais, seguida de realização de entrevista individual semiestruturada. Os roteiros da observação e da entrevista contemplaram aspectos do processo de trabalho gerencial, as ações de gestão do cuidado dos enfermeiros e as estratégias de referência e contra-referência no processo de transição do atendimento ao adolescente do serviço infantil para o adulto. As entrevistas individuais foram concedidas após o aceite e assinatura do termo de consentimento livre e esclarecido. As observações foram registradas em diário de campo e as entrevistas foram áudio-gravadas e posteriormente transcritas em arquivo Word ${ }^{\circledR}$.

Participaram do estudo enfermeiros e profissionais da equipe multidisciplinar envolvidos no 
acompanhamento ambulatorial de adolescentes que vivem com HIV/Aids por transmissão vertical nos serviços de referência infantil e adulto, totalizando dez participantes. No serviço infantil participaram dois enfermeiros, sendo um gestor da unidade ambulatorial e um gerente de enfermagem, além de um assistente social, um psicólogo, um técnico de enfermagem e um médico. No serviço adulto participaram três enfermeiros, sendo dois gestores da unidade ambulatorial e um gerente de enfermagem, e um médico. As entrevistas foram identificadas pelas letras " $E$ " e " $P$ ", representando enfermeiros e profissionais de saúde respectivamente, seguidas do número correspondente à ordem da entrevista, garantindo-se desta forma o anonimato dos participantes.

Os dados foram analisados e interpretados utilizando-se o método de análise de conteúdo de Minayo $^{(8)}$. A pesquisa foi aprovada pelo Comitê de Ética em Pesquisa com Seres Humanos do Hospital Infantil Joana de Gusmão, sob o no 004/2012. Os aspectos éticos foram respeitados em todas as etapas da pesquisa, como prevê a Resolução no 196/96, do Conselho Nacional de Saúde ${ }^{(9)}$.

\section{RESULTADOS}

\section{Apresentando a estrutura dos serviços de referência em HIV/Aids infantil e adulto}

Os serviços de referência em HIV/Aids, infantil e adulto, encontram-se estruturados de maneira distinta. O ambulatório do serviço infantil é composto por um espaço separado das demais patologias atendidas no serviço, que busca preservar o sigilo da doença $e$ garantir o acompanhamento das crianças e adolescentes com HIV/Aids por transmissão vertical. Constitui-se como um espaço de troca de experiências entre os adolescentes, porém, às vezes, esta interação é dificultada pela presença dos pais e acompanhantes, que inibem os adolescentes, conforme elucida a fala:

[...] nós passamos a fazer um dia específico de ambulatório para adolescentes, o objetivo deste dia é que a partir da sala de espera eles já tivessem um tratamento diferenciado, eles estivessem num grupo, só adolescentes, onde eles tivessem oportunidade de conversar entre eles, de discutir as suas dúvidas, os seus problemas de maneira geral [...] Mas, não é assim aquela coisa de fluir facilmente uma conversa, até porque, muitas vezes, tem um familiar acompanhando $[\ldots](P 5)$
A fim de suprir esta necessidade dos adolescentes, a equipe juntamente com o enfermeiro planeja atendimento em grupos, objetivando criar novos espaços que favoreçam essas trocas. No entanto, a falta de espaço físico constitui um desafio para o encontro dos grupos e para o enfermeiro, que não possui um consultório próprio para realizar seus atendimentos/consultas de enfermagem, como ilustra a fala:

[...] agora vamos começar um grupo de adolescentes [...] para trabalhar dois itens importantes nesse atendimento ao grupo, o paciente que não está com boa adesão ao tratamento e também a revelação diagnóstica [...] O ruim é que a enfermagem não possui uma sala própria.(E1)

O serviço infantil conta com uma equipe multiprofissional, composta por médico infectologista, enfermeiro, assistente social, psicólogo, farmacêutico e técnicos de enfermagem, o que representa uma facilidade no acompanhamento da família e do adolescente. Contudo, luta-se para manter a equipe com a composição atual diante da falta de profissionais na instituição, como demonstra o depoimento:

[...] a facilidade é que aqui a gente tem toda uma equipe á disposição, para trocar [informações][...] eu vejo que isso é uma coisa que facilita, cada um pega uma parte. Eu acho que esse trabalho [com os adolescentes] somente é possível com equipe multiprofissional $[\ldots](P 1)$

No ambulatório do serviço adulto são atendidos pacientes com diagnóstico de HIV/Aids, Hepatites, Fibrose Cística, além de outras especialidades. Nesse serviço o enfermeiro dispõe de um consultório para realizar consultas, todavia, o espaço físico também é considerado pequeno para a demanda. Segundo o enfermeiro, o ideal seria uma sala de reuniões para a equipe, família e adolescente, revelado na fala:

Eu penso que todo o atendimento precisa de uma área física adequada. Então, talvez uma sala para reunião dessa equipe, dessa equipe com a família, onde pudesse fazer oficina, enfim. Uma área para esses encontros $[\ldots](E 4)$

Ainda no serviço adulto, observa-se que o mesmo não dispõe de uma equipe multiprofissional exclusiva para atender/receber os adolescentes transferidos do 
serviço infantil, sendo a falta de profissionais neste serviço um dos obstáculos apontado pelo enfermeiro para prestar uma assistência especializada, conforme relatado:

Hoje a gente não tem [equipe multidisciplinar]. E quem sabe a gente consiga visualizar isso para o futuro, planejar que isso aconteça. Mas, para isso, a gente precisa estudar bastante, fundamentar e provar que é importante $[\ldots](E 3)$

As diferentes estruturas e constituições das equipes dos serviços de referência em HIV/Aids, infantil e adulto, são refletidas no acompanhamento ao adolescente e sua família, assim como na dinâmica das relações entre os profissionais de saúde, na organização e no funcionamento de cada serviço.

\section{Recebendo e acompanhando os adolescentes que vivem com HIV/Aids por transmissão vertical nos serviços de referência}

O trabalho com os adolescentes que vivem com HIV/Aids no ambulatório do serviço infantil é considerado um processo gradativo, que surgiu no decorrer do atendimento à criança infectada por transmissão vertical, e hoje representa a maior demanda do serviço. A disponibilidade de exames, de tratamento e de suporte psicológico, em especial quando comparadas a outros serviços, é considerada uma facilidade nesse serviço pelos profissionais que ali atuam, confirmado pelo depoimento:

[...] nós começamos a trabalhar nesta área há aproximadamente 20 anos. Na época, o futuro das crianças infectadas pelo HIV era muito incerto [...] Nós não tínhamos essa certeza, de quanto tempo essas crianças iriam viver. O tempo foi mostrando para nós o surgimento de terapêuticas antirretrovirais potentes, foi mostrando que estas crianças poderiam crescer, chegar a adolescência e a idade adulta, como estão chegando. E chegar com qualidade de vida $[\ldots](P 5)$

No ambulatório do serviço infantil a equipe de saúde acompanha as crianças expostas ao HIV desde o nascimento até a negativação ou não da sorologia para detecção do vírus. Quando a criança não negativa ela é acompanhada durante a infância e início da adolescência pelo serviço. Ao completar 15 anos de idade, o adolescente é transferido para o serviço de referência em infectologia adulto. Assim, devido ao tempo de acompanhamento e tratamento, existe entre profissionais, pacientes e família um vínculo estabelecido, como demonstra a fala do profissional:

É muito interessante, eles gostam muito da equipe [...] tem essa facilidade de saber tudo da vida deles praticamente. Porque com todo esse segredo que a doença tem, a família se preserva ao máximo [...] Quando eles estão com a gente, eles são muito abertos. Porque sabem que são pessoas que sabem [0 diagnóstico] e eles podem confiar [...](P4)

Segundo os profissionais do serviço infantil, quando transferido ao serviço adulto, o acompanhamento do adolescente não constitui mais sua responsabilidade. Desta maneira, apontam que não existe uma interação entre os serviços de referência infantil e adulto. Mesmo considerando importante a troca de informações entre os serviços e o entrosamento entre os profissionais das equipes para a continuidade do cuidado, a articulação entre as equipe e/ou profissionais dos serviços de referência não é comum. A transferência acontece sem um retorno ao serviço que encaminhou o adolescente, ou mesmo sem uma visível preocupação de integração entre os serviços, como ilustrado pela fala:

[...] Agora, adolescente é outra questão, saiu do nosso serviço, a gente não tem mais responsabilidade. A não ser que eles procurem. A gente marcou a primeira consulta [no serviço adulto] e ele não conseguiu ir, aí a gente reagenda a consulta para o serviço que ele vai. Mas saiu do nosso serviço, só se ele ou o outro serviço fizer contato, a gente não faz (P4)

No ambulatório do serviço adulto, o acompanhamento ao adolescente foi iniciado e, por algum tempo, realizado apenas pelo profissional médico, devido a falta de uma equipe multiprofissional exclusiva. Buscando dar continuidade ao acompanhamento do serviço infantil, o enfermeiro iniciou o acompanhamento deste público por meio de pré e pós-consultas de enfermagem, contudo, reforça a necessidade de uma equipe multiprofissional como suporte para o acompanhamento dos adolescentes. Observado no depoimento:

É importante que tenha uma equipe multiprofissional nesse atendimento? Muito. Muito importante! [...] Hoje a gente não tem. Hoje o que a gente tem é enfermeiro e médico $[\ldots](E 3)$ 
É revelado que este acompanhamento encontra dificuldades no serviço ambulatorial adulto, uma vez que muitos profissionais não são treinados e em número suficiente para o cuidado a este adolescente. Ainda, outro potencializador é que os adolescentes são encaminhados ao serviço sem informações pregressas do seu histórico de doença, social e familiar, uma vez que o adolescente é transferido somente com um resumo do seu tempo de acompanhamento no serviço infantil, como revela a fala:

Quando o Infantil [serviço] libera eles, com 15 anos, o pessoal faz contato com a gente pelo telefone: Oh, eu tenho o adolescente $x, y$, para ir pra vocês [...] $E$ eles vêm com um encaminhamento para o médico. Chega aqui um paciente novo para nós. Sem conhecimento prévio do histórico.(E2)

Pode-se perceber que o serviço ambulatorial infantil encontra-se melhor estruturado para acompanhar tal clientela, porém não há uma preocupação maior com a continuidade do cuidado multiprofissional no serviço adulto. Também, o atendimento no serviço ambulatorial adulto é bastante recente, visto que o processo de transição do adolescente entre os serviços de referência constitui-se um processo atual. Desta forma, a falta de investimento, planejamento dos serviços e de capacitação profissional para atender esta nova demanda, contribuem para a composição do cenário apresentado.

\section{O enfermeiro como gestor nos serviços de referência em HIV/Aids}

Observa-se que, nos serviços de referência em HIV/Aids, o enfermeiro, como gestor do cuidado e do serviço, desenvolve ações voltadas ao planejamento do processo de trabalho em enfermagem, envolvendo recursos humanos e materiais, área física, assistência de enfermagem, supervisão e dimensionamento da equipe de enfermagem e desenvolvimento de políticas institucionais.

Neste cenário, o enfermeiro define a gerência do cuidado como um ato de pensar sobre o cuidado. Uma vez que, faria parte do ato de gerenciar, organizar os fluxos de serviço, escutar a equipe de saúde, pensar e implementar os métodos de assistência e se interessar pelo cuidado de qualidade ao paciente. Entretanto, para o enfermeiro o planejamento não se sustenta/fundamenta em si, mas depende da aprovação das secretarias, gerências e direções, fato elucidado pelas falas:

Então, o meu papel é de planejamento. E uma dificuldade nesse planejamento é a forma de administração da Secretaria Estadual da Saúde, pois cada unidade hospitalar não tem autonomia e isso dificulta. Porque fazemos um planejamento, mas nem sempre ele é atendido (E4)

No serviço de referência infantil, o enfermeiro refere que realiza o gerenciamento de enfermagem, conciliando as dimensões administrativa e assistencial, ressaltando que as ações gerenciais não impedem que o enfermeiro exerça atividades assistenciais, uma vez que ambas se complementam e facilitam ao profissional a identificação de lacunas na prática. Ainda, objetiva um cuidado de qualidade apesar da escassez de recursos humanos, da sobrecarga de trabalho e da dificuldade em agregar enfermeiros ao serviço que desejem trabalhar com adolescentes que vivem com HIV/Aids, abrindo mão das suas capas de preconceito e de todo o estigma que a doença traz, conforme depoimento:

[...] a gente está vivendo agora, a falta de recursos humanos. Então, está muito mais difícil gerenciar hoje do que há dois anos. Porque os [profissionais] que a gente tem hoje já estão cansados e estressados de trabalhar excessivamente para cobrir as escalas. Por que não é fácil conseguir recursos humanos que queiram trabalhar com pacientes soropositivos. Existe ainda muito preconceito, infelizmente ainda existe. (E5)

No entanto, entre os enfermeiros do serviço adulto é observada uma dualidade entre o processo gerencial e assistencial em seu trabalho, sendo que, apesar de desenvolverem a união dessas duas dimensões em suas ações rotineiramente, acreditam ser necessário um enfermeiro responsável pela assistência e outro pela gerência do setor, desenvolvendo estas ações isoladamente, conforme a fala:

[...] o que faltaria era dois enfermeiros, teria que ter dois enfermeiros de manhã e dois à tarde para atender a demanda, ficaria um no administrativo e um no assistencial. Um enfermeiro para fazer o administrativo e assistencial, não tem como! Em algum lugar vai ficar falha... (E2) 
No serviço ambulatorial adulto, as mudanças para o atendimento do adolescente com HIV/Aids foram realizadas em caráter de urgência e sem planejamento prévio, impulsionadas pela demanda do serviço. Como consequência não houve a formação de uma equipe multiprofissional exclusiva para este acompanhamento, levando o enfermeiro a encontrar dificuldade para se inserir no atendimento ao adolescente com HIV/Aids. Isto é percebido na fala:

Mas, não foi planejado dessa forma, até pela falta de profissionais, porque eu não tenho toda uma equipe. $E$ um enfermeiro não é suficiente para tudo. Então, não foi pensado especificamente para isso [atendimento do adolescente com HIV/Aids](E4)

Neste serviço, o enfermeiro exerce diferentes atribuições voltadas ao cuidado das pessoas que vivem com HIV/Aids, sendo que, a consulta de enfermagem constitui uma das principais ferramentas para acompanhar este adolescente, envolvendo interação, empatia e respeito. O enfermeiro desempenha o papel de suporte e é o referencial do paciente no serviço, sendo procurado pelos pacientes para conversar e auxilia-los a encontrar maneiras de lidar com uma doença ainda estigmatizada como no caso da Aids, conforme a fala do enfermeiro:

Eles pensam: Chegando lá eu sei que eu vou falar com a enfermeira e ela vai me dar uma luz. E é isso que eles veem na gente. (E3)

Foi apontada a importância de um planejamento conjunto envolvendo a direção e gerências da instituição, com gestão e organização dos recursos para um atendimento/cuidado adequado ao adolescente, como demonstrado pelo depoimento:

Isso é um serviço que deveria ser organizado em conjunto, gerência técnica, gerência de enfermagem e direção geral. Discutir para dizer se a gente vai passar a atender, e o que a gente precisa. Porque geralmente não é feito isso. Muitas vezes, eu acho que existe uma necessidade grande e as coisas vem sem planejamento prévio, vão se encaixando no serviço de acordo com a pressão da necessidade $[\ldots](E 4)$

Os profissionais dos serviços de referência, infantil e adulto, afirmam que a gestão dos serviços não depende somente do enfermeiro, mesmo sendo este o profissional mais indicado a gerenciar o cuidado e serviço por manter-se articulado e envolvido com a equipe de saúde e paciente. A participação de uma equipe multiprofissional, assim como a abertura dos profissionais envolvidos nestas relações de cuidado para a inserção do enfermeiro na reformulação do serviço de atendimento ao adolescente que vive com HIV/Aids por transmissão vertical são consideradas essenciais, conforme a fala:

Gestão é uma coisa muito mais ampla, que não depende só do enfermeiro. [...] mas também de outros profissionais [...] A partir do momento que a médica começa a reconhecer o trabalho do enfermeiro, ela começa a incluir, ela incluindo o enfermeiro, a gente começa a incluir outras questões (E3)

Assim, em ambos os serviços de referência permeia entre os profissionais um sentimento de frustração relacionada a pouca e frágil gestão desenvolvida nos serviços, apontando a necessidade de um gestor com foco, conhecimento, criatividade, interesse de mudar e voz dentro do serviço para que mudanças ocorram. Como também, para que se desenvolva uma participação ativa no planejamento e estruturação do serviço de acompanhamento ao adolescente que vive com HIV/Aids por transmissão vertical. No entanto, os participantes revelam que o serviço carece de um gestor com este perfil, conforme elucida a fala:

O que me dói é essa falta de organização, essa falta de gestão. Eu não sei se é pela quantidade de serviço que têm, ou se é pela ingerência do hospital no serviço oferecido [...] No ambulatório, eu não tenho esse poder de mudança. E quem tem, não consegue mudar também, por que não tem alguém que se interesse. (E3)

Percebe-se que o enfermeiro como gestor nos serviços de referência em HIV/Aids encontra inúmeros desafios para o planejamento e execução das ações necessárias a gerência do cuidado e do serviço, como: necessidade de apoio dos gestores, frágil relação com os membros da equipe, escassez de recursos humanos, materiais e de infraestrutura e capacitação insuficiente ou inexistente para profissionais já atuantes. Além do conflito entre as ações gerenciais e assistenciais que dificultam a inserção do enfermeiro no planejamento do serviço levando ao sentimento de frustração e desmotivação profissional. 


\section{DISCUSSÃO}

Neste estudo pode-se observar que os serviços ambulatoriais de referência em HIV/Aids, infantil e adulto, encontram-se estruturados de maneiras distintas. No entanto, encontram os mesmos obstáculos no cuidado ao adolescente que vive com HIV/Aids por transmissão vertical, como a falta de espaço físico, autonomia e profissionais capacitados, para atender esta demanda.

O serviço de saúde é considerado um espaço adequado para construção de vínculo e interação entre o profissional de saúde, o adolescente e o familiar. Sendo este espaço, um local de investimento de ações assistenciais e existenciais destes indivíduos, que é vivenciado pelo adolescente com HIV/Aids por transmissão vertical desde o seu nascimento até início da vida adulta(10). Assim, os serviços precisam estar estruturados para este atendimento, e oferecer profissionais capacitados para orientação e aconselhamento ${ }^{(11)}$.

Questões estruturais e de organização aparecem em outros estudos como problemas comuns, se tratando de administração pública hospitalar no Brasil, na qual a autonomia da instituição é limitada, e o planejamento das ações do enfermeiro gestor esbarra na hierarquia, burocracia e no poder normativo das instituições ${ }^{(12)}$. Neste sentido, questões como dispor de quantitativo e qualitativo de recursos humanos e materiais, possuir autonomia para gerenciar unidade e equipe, manter bom relacionamento interpessoal e principalmente participar na tomada de decisões contribuem para a satisfação profissional do enfermeiro(13). Consequentemente, o oposto acaba por atrapalhar o desempenho de suas funções gerenciais.

Assim, a transição do adolescente entre os serviços é considerada um desafio na atenção a este público, apontado pela falta de planejamento, serviços adultos pouco preparados para receber adolescentes em condições crônicas, falta de comunicação entre os serviços de referência e falta de apoio institucional ${ }^{(4)}$. Neste sentido, a produção da integralidade do cuidado, princípio do SUS, exige que a gestão tenha como objetos de ação e política de governo, a produção de cuidado e o trabalho em saúde, por meio da interação entre os diversos serviços com seus gestores, trabalhadores e usuários, como arranjo necessário para a continuidade da atenção ${ }^{(14)}$.

Atualmente os serviços públicos de saúde carecem de uma gestão ampliada e responsável, na qual o gestor exerça uma liderança democrática no sentido de trabalhar juntamente com a equipe, compartilhando conhecimentos e habilidades, construindo assim um serviço que promova as trocas e o desenvolvimento das pessoas. No entanto, para isso os gestores esbarram em questões como falta de financiamento, ausência de redes integradas, pouca sustentabilidade política e institucional, falta de profissionais, entre outras ${ }^{(15)}$ que corroboram com os achados deste estudo.

A importância da consolidação de uma equipe multiprofissional trabalhando em conjunto ao gestor, direcionando as ações de trabalho, na promoção, prevenção e/ou recuperação da saúde, em qualquer nível de atenção se torna evidente, especialmente se tratando da transição do adolescente com HIV/Aids do serviço infantil para o adulto. Desta forma, a atuação de múltiplos agentes, que compõem a equipe multiprofissional, configuram um trabalho coletivo que é tido como importante para a integração da assistência ${ }^{(16)}$.

Contudo, os serviços de referência apresentados neste estudo por terem sido iniciados por profissionais médicos, preservando o modelo biomédico de atuação, tendem a prejudicar a interação dos demais profissionais. De acordo com outro estudo, a forte influência do modelo biomédico nos serviços especializados em HIV/Aids, acarreta em dificuldades de articulação entre os serviços, e requer a necessidade de pensar em uma integralidade ampliada, construída por meio de uma relação articulada entre os mesmos ${ }^{(17)}$.

O enfermeiro, por sua vez, tenta se inserir no atendimento ao adolescente que vive com HIV/Aids nos serviços de referência por meio de atribuições gerenciais e da consulta de enfermagem, a qual se apresenta como uma importante ferramenta para gerência do cuidado de enfermagem, aproximando profissional/paciente/familiar, estreitando laços, facilitando o vínculo e contribuindo para o acompanhamento integral destes pacientes considerando seu contexto biopsicossocial.

Neste sentido, a gerência do cuidado é revelada pelos enfermeiros deste estudo como ato de pensar sobre o cuidado, visto que gerenciar envolve mais que ações meramente burocráticas, mas uma assistência consciente e completa ao paciente. $\mathrm{O}$ ato de gerenciar encontra-se sob um processo integral, fundamentado em administrar e cuidar, e não dividido em ações distintas, que se convergem, ou que sejam dicotômicas entre si, mas composto por ações que se completam ${ }^{(18)}$.

No entanto, aparece no serviço adulto uma separação entre as ações assistenciais e gerenciais realizadas pelo enfermeiro, evidenciado quando o mesmo 
acredita ser necessário um enfermeiro para cada esfera de atenção. Este pensamento se fundamenta no próprio cenário da saúde hospitalar, que apresenta o processo de cuidar e administrar como atos paralelos nas instituições, uma vez que o cuidado constitui uma marca no processo de trabalho da enfermagem, que pode apresentar-se de maneira direta ou indireta. Assim os eixos assistenciais e gerenciais, acabam sendo divisores do processo de trabalho do enfermeiro, levando este a ações fragmentadas de um pensamento que deveria ser, em sua essência, um só: o cuidar gerenciando e o gerenciar cuidando ${ }^{(18-19)}$.

No serviço infantil, o enfermeiro refere unir as ações assistenciais e gerenciais em seu processo de trabalho, uma situação contrária à encontrada no serviço adulto. Estudos revelam que, historicamente, o gerenciamento de enfermagem vem sofrendo alterações com o objetivo de articular os modelos administrativos e assistenciais no seu cotidiano, focando sempre no cuidado ao paciente, considerando que o trabalho gerencial do enfermeiro busca por finalidade a qualidade do cuidado prestado(1920). Com isso, o que muda não é o objetivo do trabalho do enfermeiro, mas, a sua linguagem, o qual busca não se referir mais ao cuidado e a gerência como ações separadas, mas incorporar seus saberes, se referindo ao cuidado e a gerência como ações completas que se completam, ou seja, passando a viver a gerência do cuidado de enfermagem ${ }^{(18)}$.

Os resultados deste estudo mostram que 0 enfermeiro gestor deve ser interessado, ter iniciativa e participar ativamente no serviço. Semelhante ao evidenciado pela literatura, que apresenta o gestor como o profissional com postura ética, criativo, incentivador, empreendedor, imparcial, com habilidade técnica, que sabe direcionar, avaliar e planejar, além de saber gerenciar equipes e processos ${ }^{(12,16)}$, que almeje penetrar no desconhecido e que inspire uma visão compartilhada do serviço de acompanhamento em HIV/Aids ${ }^{(21)}$. Apesar do perfil supracitado ser considerado o ideal para um enfermeiro gestor, por vezes, o profissional que ocupa este cargo não consegue o compor, acarretando em conflitos com a equipe, desorganização do serviço, frustrações pessoais e consequentemente prejudicando o acompanhamento do adolescente que vive com HIV/Aids.

Estudos revelam que nem sempre a pessoa indicada a um cargo de gestor possui competência necessária para alcançar bons resultados, tendendo a queda na qualidade da assistência ${ }^{(12)}$. No entanto, cabe ressaltar que a grande quantidade de ações a serem administradas pelo enfermeiro, muitas vezes ocasionada pela ausência de uma equipe multiprofissional de suporte, assim como as constantes cobranças em seu cotidiano de trabalho acabam interferindo em seu desempenho e impossibilitando a implementação do planejamento proposto ${ }^{(12)}$.

Além disso, o enfermeiro, por vezes, na sua atuação profissional tende a aceitar determinadas condições de trabalhos como falta de recursos humanos e materiais, sobrecarga de trabalho, relações interpessoais conflituosas, dentre outras, que contribuem para a desarmonia institucional ${ }^{(22)}$. Contudo, espera-se que o enfermeiro tenha sensibilidade e preparo para perceber seu lugar dentro da equipe e serviços de saúde, se envolvendo nas decisões gerenciais a fim de reivindicar as necessidades pertinentes ao acompanhamento do adolescente que vive com HIV/Aids por transmissão vertical de forma a contemplar suas necessidades integralmente e inserir-se nesse contexto como profissional habilitado e competente para agir no processo de promoção e reabilitação deste adolescente como educador em saúde ${ }^{(23)}$.

\section{CONCLUSÕES}

Os resultados revelam os desafios para a atuação do enfermeiro como gestor nos serviços de referência em HIV/Aids no cuidado ao adolescente que vive com HIV/Aids por transmissão vertical, especialmente no momento de transição do cuidado.

Tais resultados nos levam a vislumbrar a importância do desenvolvimento de competências do enfermeiro para a participação em todos os âmbitos gerenciais das instituições, com atitude ético-política, visando que o processo de transição do cuidado ao adolescente que vive com HIV/Aids entre os serviços de referência seja fundamentado no cuidado integral e de qualidade.

Por fim, ressalta-se a importância de ações de gestão em tais serviços, desvelados pela necessidade de investimentos em infraestrutura, maior interação e comunicação entre as equipes de saúde, apoio e planejamento das ações, formação e capacitação profissional para gestão em saúde por meio da criação de estratégias que visem formar e desenvolver profissionais com conhecimento, habilidades e atitudes voltadas à atuação gerencial em serviços especializados. 


\section{REFERÊNCIAS}

1. Ferrand RA, Bandason T, Musvaire P, Larke N, Nathoo $K$, Mujuru $\mathrm{H}$, et al. Causes of Acute Hospitalization in Adolescence: Burden and Spectrum of HIV-Related Morbidity in a Country with an Early-Onset and Severe HIV Epidemic: A Prospective Survey. PLoS Med. 2010; 7(2):1000178.

2. Motta MGC, Pedro ENR, Coelho DF, Wachholz NIR, Greff AP. Trajetória de uma pesquisa com a temática HIV/aids: limites e (im) possibilidades. Rev Gaúcha Enferm. Porto Alegre (RS), 2009 jun;30(2):343-7.

3. Paula CC, Cabral IE, Souza ÍEO. O cotidiano do ser-

adolescendo com aids: movimento ou momento existencial?. Esc. Anna Nery. 2009;13(3):632-639.

4. Machado DM, Succi RC, Turato ER. Transitioning adolescents living with HIV/AIDS to adult-oriented health care: an emerging challenge. J. Pediatr. Rio de Janeiro (RJ), 2010; 86(6): 465-72. 5. Barros LBL, Lopes JL. A legislação e a sistematização da assistência de enfermagem. Enfermagem em foco. 2010; 1(2): 63-65.

6. Furukawa PO, Cunha ICKO. Profile and competencies of nurse managers at accredited hospitals. Rev. Latino-Am. Enfermagem. 2011; 19(1): 106-114.

7. Boudreau ME, Fisher CM. Providing Effective Medical and Case Management Services to HIV-Infected Youth Preparing to Transition to Adult Care. Journal Of The Association Of Nurses In Aids Care. 2012; 23(4): 318-328.

8. Minayo MCS. O desafio do conhecimento: pesquisa qualitativa em saúde. São Paulo: Hucitec; 2007.

9. Brasil. Ministério da Saúde. Conselho Nacional de Saúde. (1996) - Resolução 196, de 10 de outubro de 1996: diretrizes e normas regulamentadoras de pesquisa envolvendo seres humanos. Brasília (DF).

10. Paula CC, Cabral IE, Souza IEO. O (não)dito da AIDS no cotidiano de transição da infância para a adolescência. Rev. Bras. Enferm. 2011; 64(4): 658-664.

11. Paiva V, Ayres JRCM, Segurado AC, et al. A sexualidade de adolescentes vivendo com HIV: direitos e desafios para o cuidado. Ciênc. saúde colet. 2011; 16(10): 4199-4210.

12. Motta KAMB, Munari DB, Costa FN. Os Pontos Críticos das Atividades do Enfermeiro-Gestor no Hospital Público. REPSIPP. 2009; 1(1).

13. Nunes CM, Tronchin DMR, Melleiro MM, Kurcgant $P$.

Satisfação e insatisfação no trabalho na percepção de enfermeiros de um hospital universitário. Rev. Eletr. Enf. [Internet] 2010;12(2):252-7. Available from: http://www.fen.ufg.br/revista/v12/n2/v12n2a04.htm.

14. Baduy RS, Feuerwerker LCM, Zucoli M, Borian JT. A regulação assistencial e a produção do cuidado: um arranjo potente para qualificar a atenção. Cad. Saúde Pública. 2011; 27(2):295-304. 15. Ditterich RG, Moyses ST, Moyses SJ. O uso de contratos de gestão e incentivos profissionais no setor público de saúde. Cad. Saúde Pública. 2012; 28(4):615-625.

16. Manenti SA, Ciampone MHT, Mira VL, Minami LF, Soares JMS. $O$ processo de construção do perfil de competências gerenciais para enfermeiros coordenadores de área hospitalar. Rev Esc Enferm USP. 2012; 46(3):727-33.

17. Borges MJL, Sampaio AS, Gurgel IGD. Trabalho em equipe e interdisciplinaridade: desafios para a efetivação da integralidade na assistência ambulatorial às pessoas vivendo com HIV/Aids em Pernambuco. Ciênc. saúde colet. 2012; 17(1):147-156.

18. Christovam BP, Porto IS, Oliveira DC. Gerência do cuidado de enfermagem em cenários hospitalares: a construção de um conceito. Rev Esc Enferm USP. 2012; 46(3):734-41.

19. Hausmann M, Peduzzi M. Articulação entre as dimensões gerencial e assistencial do processo de trabalho do enfermeiro. Texto Contexto Enferm, Florianópolis (SC), 2009 abr/jun; 18(2): 258-65.

20. Almeida ML, Segui MLH, Bernardino E, Meier MJ, Peres AM. Direção ou Coordenação? Repensando a representatividade institucional da Enfermagem. Rev Bras Enferm.; 2011 mai/jun; 64(3): 521-6.

21. Luz ED, Silva RF, Avelar SA. Percepção do enfermeiro sobre seu papel no exercício da Liderança. Rev Enferm Integrada., Ipatinga (MG); 2010 jul/ago; 3(1):442-52.
22. Girondi JBR, Backes MTS, Argenta MI, Meirelles BHS, Santos SMA. Risco, vulnerabilidade e incapacidade: reflexões com um grupo de enfermeiras. Rev. Eletr. Enf. [Internet]. 2010;12(1):20-7. Available from: http://www.fen.ufg.br/revista/v12/n1/v12n1a03.htm. 23. Albuquerque JG, Pinheiro PNC, Lopes MVO, Machado MFAS. Conhecimento deficiente acerca do HIV/AIDS em estudantes adolescentes: identificação de diagnóstico de enfermagem da NANDA. Rev. Eletr. Enf. [Internet]. 2012 jan/mar; 14(1):104-11. Available from:

http://www.fen.ufg.br/revista/v14/n1/v14n1a12.htm.

Artigo recebido em 17/12/2013.

Aprovado para publicação em 25/02/2014.

Artigo publicado em 30/06/2014. 